\title{
Beneficial effects of dietary fibre supplementation of a high-fat diet on fetal development in rats
}

\author{
Yan Lin ${ }^{1}$, Xing-fa Han ${ }^{1}$, Zheng-feng Fang ${ }^{1}$, Lian-qiang Che ${ }^{1}$, Jerry Nelson ${ }^{2}$, Tan-hai Yan ${ }^{1}$ and De Wu ${ }^{1 *}$ \\ ${ }^{1}$ Key Laboratory for Animal Disease Resistance Nutrition, Animal Nutrition Institute, Sichuan Agricultural University, Ya'an \\ 625014, People's Republic of China \\ ${ }^{2}$ Divisions of Plant Sciences, University of Missouri, Columbia, MO, USA
}

(Received 6 July 2010 - Revised 17 December 2010 - Accepted 6 January 2011 - First published online 13 April 2011)

\section{Abstract}

The objective of the present study was to investigate the effects of the addition of fibre and the antioxidant $N$-acetylcysteine (NAC) to fatrich diets on fetal intrauterine development in rats. A total of eighty virgin female Sprague-Dawley rats were fed a control diet, a high-fat diet (HF), a high-fat and high-fibre diet (HFF) or a high-fat NAC diet until day 19.5 of gestation. Maternal HFF consumption resulted in a significantly higher mean fetal number and placental weight than in the other groups $(P<0 \cdot 05)$. The HFF diet significantly abrogated HFinduced decreases in maternal serum and placental superoxide anion and hydroxyl radical scavenging capacities $(P<0 \cdot 05)$; partially abrogated HF-induced increases in maternal serum and placental malondialdehyde (MDA) and protein carbonyl concentrations (maternal serum MDA and placental protein carbonyl, $P<0.05)$; resulted in significantly higher fetal liver total superoxide dismutase (SOD), $\mathrm{Cu}$ - and $\mathrm{Zn}$-containing SOD and Mn-containing SOD (Mn-SOD) activities than in the HF group $(P<0 \cdot 05)$. Furthermore, mRNA expressions of hypoxia-inducible factor 1- $\alpha$, thioredoxin 2 and Mn-SOD in fetal liver and Mn-SOD in fetal heart and placental GLUT3 in the HFF group were higher than those in the other groups $(P<0 \cdot 05)$. The inclusion of dietary fibre in the HF diet was more effective than NAC supplementation in maintaining maternal serum and placental superoxide anion and hydroxyl radical scavenging capacities close to those of the control. These results suggest that maternal fibre intake during pregnancy is beneficial for fetal intrauterine development possibly through the improvement of maternal, placental and fetal antioxidant capacities and placental nutrient transfer capacity.

\section{Key words: Dietary fibre: High-fat diet: Antioxidants: Nutrient transfer: Fetal development}

The balance between cellular oxidising and reducing forces regulates key transcription factors that influence cell signalling pathways involved in proliferation and differentiation ${ }^{(1,2)}$. Oxidising and reducing reactions occur constantly in cells as part of normal aerobic life, resulting in the production of oxygen-derived radicals (reactive oxygen species (ROS)). ROS act as primary or secondary messengers to promote cell growth or death but can activate a variety of signalling pathways that inflict damage on cells if produced at high levels. Antioxidants provide important intracellular defence against damage by ROS. A delicate balance between ROS production and antioxidant capability maintains homeostasis; an imbalance between the two results in oxidative stress.

Throughout development, the embryo requires energy from aerobic respiration; however, the resultant fetal and placental ROS and oxidative stress can greatly affect organogenesis and growth. In addition, there are significant correlations between maternal and fetal oxidative stress biomarkers and antioxidants, suggesting that a maternal oxidant/antioxidant imbalance causes oxidative stress in the fetus. A certain amount of oxidative stress is needed to allow for the normal progression of embryonic and fetal growth, but alterations in oxidative stress and a perturbed antioxidant system can cause pregnancy complications including miscarriage and growth restriction ${ }^{(3)}$.

The embryo possesses a set of activities of antioxidant enzymes including $\mathrm{Cu}$ - and $\mathrm{Zn}$-containing superoxide dismutase (Cu,Zn-SOD), Mn-containing SOD (Mn-SOD), glutathione peroxidase and thioredoxins ( $\operatorname{Trx}$ ). It is likely that changes in the expressions of antioxidants in the fetus are an adaptive response to counter the effects of changing oxidative stress in the mother ${ }^{(4)}$, and that the failure of this response has adverse consequences for the fetus. The mechanisms involved in the deterioration of the fetus in response to maternal and

Abbreviations: Cu,Zn-SOD, Cu- and Zn-containing superoxide dismutase; HF, high-fat diet; HFF, high-fat and high-fibre diet; HIF-1 $\alpha$, hypoxia-inducible factor 1- $\alpha$; MDA, malondialdehyde; Mn-SOD, Mn-containing superoxide dismutase; NAC, $N$-acetylcysteine; ROS, reactive oxygen species; SOD, superoxide dismutase; Trx, thioredoxin; T-SOD, total superoxide dismutase. 
placental oxidative stress are multifaceted. Previous studies have shown that oxidative damage to the trophoblast and placental tissues are key factors in early fetal loss ${ }^{(5)}$, that ROS generation induced by high nutrient intake in early pregnancy suppresses placental growth, resulting in reduced placental and fetal size ${ }^{(6)}$, and that placental dysfunction during pregnancy is associated with fetal growth retardation and the metabolic syndrome in later life $\mathrm{e}^{(7-9)}$. Based on these data, we propose that one process contributing to fetal death during oxidative stress is a compromised placenta and the decreased maternal-fetal transfer of nutrients across an impaired placental-decidual interface.

Maternal obesity and overfeeding alter the oxidant status in the fetus. A maternal diet rich in fat shifts the fetal cellular redox environment to a more oxidised state ${ }^{(10)}$, retards embryonic progression, causes embryo toxicity and results in miscarriage ${ }^{(2,11)}$. In addition, maternal high-fat diets can alter fetal programming and predispose children to CVD and metabolic disease in adult life ${ }^{(7,12)}$. These observations indicate that maternal fat and energy intake can influence the metabolic fate of the fetus. However, the mechanisms by which maternal energy intake affects maternal and fetal oxidant/antioxidant status and the availability of appropriate therapies to obviate these changes are largely unknown.

Previous reports have shown that diets rich in fibre increased antioxidant status and had important implications for health ${ }^{(13)}$, and that the consumption of dietary fibre was inversely associated with the risk of $\mathrm{CHD}^{(14)}$. This suggests that the addition of dietary fibre to a HF, Western-style diet may be beneficial to health. However, studies investigating the effects of a high-fat diet in combination with maternal fibre intake on maternal and fetal antioxidant capacities and fetal development are limited.

$\mathrm{N}$-acetylcysteine (NAC) is a sulphur-based amino acid and a potent antioxidant that can minimise oxidative stress and its associated downstream negative effects. We investigated whether supplementation of a high-fat diet with fibre and NAC was effective in abrogating dietary fat-induced maternal and placental oxidative stress and promoting fetal development. We compared maternal and fetal oxidative responses to dietary fibre and NAC to study the mechanisms involved in dietary fibre-induced changes in antioxidant status. We investigated the effects of the supplements on the nutrient transfer capacity of the placenta to determine whether maternal and fetal antioxidant capacities affected fetal growth and development through processes that altered placental structure and function.

\section{Materials and methods}

\section{Animals and diets}

A total of eighty virgin female Sprague-Dawley rats were placed on an ad libitum standard laboratory chow diet (20\% protein) and water until pregnancy was confirmed by the observation of vaginal plugs. Pregnant animals were fed ad libitum on one of the four diets: a normal-protein diet (C group); a high-fat diet (HF group); a high-fat and high-fibre diet (HFF group); a high-fat NAC diet (NAC group, $0 \cdot 1 \mathrm{~g} / \mathrm{kg}$ ), respectively, from the first day of pregnancy. Dietary fat consisted of soyabean oil, rapeseed oil and pig lard because of their wide consumption in the human diet. Fibre was provided by oat and wheat bran with a ratio of 1:1. Diets were prepared on a weekly basis to reduce the risk of oxidative rancidity, and all diets were stored at $4^{\circ} \mathrm{C}$. The compositions of the experimental diets are listed in Table 1. Animals were then housed individually in galvanised-steel cages with free access to food and water until sample collection was performed on day $19 \cdot 5$ of gestation. All aspects of animal handling were approved by the Animal Care and Use Committee of the Sichuan Agricultural University and the National Research Council's Guide for the Care and Use of Laboratory Animals.

\section{Collection of blood and tissue samples}

Rats were anaesthetised in sealed jars containing cotton soaked with $350 \mu \mathrm{l}$ isoflurane as described previously ${ }^{(15)}$. Maternal blood was collected and centrifuged at $4000 \mathrm{rpm}$ for $10 \mathrm{~min}$ at $4^{\circ} \mathrm{C}$; serum was collected and stored at $-20^{\circ} \mathrm{C}$ until analysis. Immediately after the maternal rats were killed, the fetus and the placenta were removed and weighed. The fetal liver, heart and placenta were frozen in liquid $\mathrm{N}_{2}$, and stored at $-70^{\circ} \mathrm{C}$ until analysis. Part of the placenta was used for histological examination.

\section{Measurements and analytical methods}

Histological examination of placental tissues. Small $0.5 \times 0.5 \mathrm{~cm}$ segments of placental tissues were cut and rinsed with ice-cold phosphate buffer saline. Samples were fixed in $10 \%$ neutral-buffered formalin, processed routinely for histological examination, cut at 5-6 $\mu \mathrm{m}$ thick, and then stained with haematoxylin and eosin for routine histological examination.

Table 1. Compositions of the experimental diets based on the American Institute of Nutrition-93 diet

\begin{tabular}{lcclc}
\hline & $\mathrm{C}$ & $\mathrm{HF}$ & $\mathrm{HFF}$ & $\mathrm{NAC}$ \\
\hline Ingredient (g/kg DM) & & & & \\
$\quad$ Maize starch & 530.492 & 350.492 & 135.492 & 349.492 \\
Wheat bran & 0 & 0 & 125 & 0 \\
Oat & 0 & 0 & 125 & 0 \\
Casein & 200 & 200 & 165 & 200 \\
Sucrose & 100 & 100 & 100 & 100 \\
Soyabean oil & 70 & 150 & 150 & 150 \\
Lard & 0 & 100 & 100 & 100 \\
Vitamin mixture & 10 & 10 & 10 & 10 \\
Mineral mixture & 35 & 35 & 35 & 35 \\
L-Cysteine & 2 & 2 & 2 & 2 \\
Cellulose & 50 & 50 & 50 & 50 \\
Choline bitartrate & 2.5 & 2.5 & 2.5 & 2.5 \\
$t$-BHQ & 0.008 & 0.008 & 0.008 & 0.008 \\
$\quad$ NAC & 0 & 0 & 0 & 1 \\
Chemical composition (DM) & 17.00 & 17.00 & 17.00 & 17.00 \\
Protein (\%) & 7 & 25 & 25 & 25 \\
Fat (\%) & 19.50 & 23.37 & 20.79 & 23.38 \\
Gross energy (kJ/g) & & &
\end{tabular}

C, control group; HF, high-fat group; HFF, high-fat and high-fibre group; $\mathrm{NAC}, \mathrm{N}$-acetylcysteine group; $t$-BHQ, tert-butyl hydroquinone. 
Blood sample biochemical analyses. Maternal serum levels of glucose, TAG, protein and HDL were determined with commercial kits (Leadmanbio, Beijing, China) on an autoanalyser (BMD/Hitachi 705; Hitachi Limited, Tokyo, Japan).

Hydroxyl radical scavenging capacity of maternal serum and the placenta. Hydroxyl radical scavenging capacity was assayed as described previously ${ }^{(16)}$ with slight modifications. The principle of the assay is the quantification of malondialdehyde (MDA), the degradation product of 2-deoxyribose, by its condensation with tetrabutylammonium. Hydroxyl radical was generated by the $\mathrm{Fe}^{3+}$-ascorbateEDTA- $\mathrm{H}_{2} \mathrm{O}_{2}$ system (Fenton reaction). Absorbance was measured at $532 \mathrm{~nm}$ against an appropriate blank solution. All tests were performed five times, and percentage inhibition was evaluated by comparing the test and control groups.

Superoxide anion scavenging capacity of maternal serum and the placenta. Superoxide anion scavenging capacity was measured by a reduction in nitroblue tetrazolium according to a previously reported method ${ }^{(17)}$. The xanthine-xanthine oxidase system was used to determine the superoxide anion scavenging activity. All tests were performed five times, and percentage inhibition was evaluated by comparing the test and control groups.

Assay of malondialdehyde and protein carbonyl concentrations in maternal serum and the placenta. MDA concentrations in serum and the placenta were quantified by the tetrabutylammonium method ${ }^{(18)}$, which is based on the reaction of MDA with thiobarbituric acid to form a pink chromogen. Data were normalised to protein content and are expressed as $\mathrm{nmol} / \mathrm{mg}$ protein. Protein carbonyl concentrations were determined from reactions with dinitrophenylhydrazine, using a commercially available kit (Oxiselect $^{\mathrm{TM}}$ protein carbonyl ELISA; Cell Biolabs, San Diego, CA, USA) according to the manufacturer's instructions. Absorbance was measured at $370 \mathrm{~nm}$, and concentrations were calculated using a molar extinction coefficient of $22000 \mathrm{M} / \mathrm{cm}$ at $370 \mathrm{~nm}$ after subtraction of the blank absorbance.

Assay of total superoxide dismutase, copper, zinc-superoxide dismutase and manganese-superoxide dismutase activities in fetal liver. Total SOD (T-SOD) activity was measured using an indirect competition assay between SOD and the indicator compound, nitroblue tetrazolium, for superoxide produced by xanthine-xanthine oxidase according to a previously described method ${ }^{(19)}$. Activity units were determined by defining 1 unit of T-SOD activity as the amount of sample protein capable of inhibiting the reduction in nitroblue tetrazolium by $50 \%$ of maximum inhibition. Data were normalised to protein content and are expressed as $\mathrm{U} / \mathrm{mg}$ protein. Activities of $\mathrm{Cu}, \mathrm{Zn}-\mathrm{SOD}$ and Mn-SOD were determined by the xanthine-xanthine oxidase method according to the procedures described by Sun et al. ${ }^{(20)}$ and Nagai et al. ${ }^{(21)}$. Data were normalised to protein content and are expressed as $\mathrm{U} / \mathrm{mg}$ protein.

RNA preparation and quantitative real-time $P C R$ of the placenta, and fetal liver and heart. Total RNA was isolated from the placenta and fetal liver and heart using a guanidine isothiocyanate-based reagent (TRIzol reagent; TaKaRa, Shiga, Japan) according to the manufacturer's instructions. Quantitative and qualitative analyses of isolated RNA were assessed from the ratio of absorbance at 260 and $280 \mathrm{~nm}$ and agarose gel electrophoresis. Total RNA $(5 \mu \mathrm{g})$ was used as a template to synthesise complementary DNA for quantitative real-time PCR. The genes listed in Table 2 were amplified by DNAspecific primers (Invitrogen, Carlsbad, CA, USA) on a Thermal

Table 2. Sequences of primers for PCR amplifications

\begin{tabular}{|c|c|c|c|}
\hline Gene & Primers & Length (bp) & GenBank \\
\hline$G P x 1$ & $\begin{array}{l}\text { F: 5'-GGCTCCCTGCGGGGCAAGGT-3' } \\
\text { R: 5'-TGTACTTGGGGTCGGTCATG-3' }\end{array}$ & 112 & NM_030826.3 \\
\hline$C u, Z n-S O D$ & $\begin{array}{l}\text { F: 5'-GAACCAGTTGTGGTGTCAGGA-3' } \\
\text { R: 5'-CTCCAACATGCCTCTCTTCATC-3' }\end{array}$ & 169 & NM_017050 \\
\hline$M n-S O D$ & $\begin{array}{l}\text { F: } 5^{\prime} \text {-AGAGTTGCTGGAGGCTATCAAG-3' } \\
\text { R: 5'-CAGTGGGTCCTGATTAGAGCA-3' }\end{array}$ & 166 & NM_017051 \\
\hline Trx1 & $\begin{array}{l}\text { F: } \text { 5'-CCCTTCTTTCATTCССТCTGTG-3' }^{\prime} \text { R: 5'-GAACTCCCCAАCCTTTTGACC-3' }\end{array}$ & 150 & NM_053800 \\
\hline $\operatorname{Tr} x 2$ & $\begin{array}{l}\text { F: 5'-CGTACAATGCTGGTGGTCTAAC-3' } \\
\text { R: 5'-GTCTTGAAAGTCAGGTCCATCC-3' }\end{array}$ & 110 & NM_053331.2 \\
\hline$H I F-1 \alpha$ & $\begin{array}{l}\text { F: 5'-CATCTCCACCTTCTACCCAAGT-3' } \\
\text { R: 5'-GACTCTCTTTCCTGCTCTGTCTG-3' }\end{array}$ & 110 & AF057308 \\
\hline Slc2a1 & $\begin{array}{l}\text { F: } 5^{\prime}-C C A \text { GAT ACC TAC CGG TTA- } 3^{\prime} \\
\text { R: } 5^{\prime}-\text { TCC TTT AAC TGC AGC TGA-3 } 3^{\prime}\end{array}$ & 145 & NM_138827.1 \\
\hline Slc2a3 & $\begin{array}{l}\text { F: } 5^{\prime}-\text { CTG AAA TGG AAA GGG TGT-3' } \\
\text { R: 5'-CCA TGTC TTA CAC ACA AGC-3' }\end{array}$ & 112 & NM_017102.2 \\
\hline Slc7a1 & $\begin{array}{l}\text { F: 5'-TGTCCTGGTCTTGTGCTTC-3' } \\
\text { R: 5'-CCCTCCCTCACCGTATTTC-3' }\end{array}$ & 133 & NM_013111.2 \\
\hline Slc38a2 & $\begin{array}{l}\text { F: 5'-CCTTGGGCTTTCTTATGC-3' } \\
\text { R: 5'-GAGGAGGTGAACGGAGTA-3' }\end{array}$ & 100 & NM_181090.2 \\
\hline Slc38a4 & $\begin{array}{l}\text { F: } \text { 5'-GGTATCTTGGGCTTGTCC-3' }^{\prime} \text { R: 5'-CCTTCCTTGGCTGTCTTC-3' }\end{array}$ & 125 & NM_130748.1 \\
\hline$\beta$-Actin & $\begin{array}{l}\text { F: } 5^{\prime}-\text { CAC AGC TGA GAG GGA AAT-3' } \\
\text { R: } 5^{\prime}-\text { TCA GCA ATG CCT GGG TAC-3' }\end{array}$ & 155 & NM_031144 \\
\hline
\end{tabular}

GPx1, glutathione peroxidase 1; F, forward; R, reverse; $\mathrm{Cu}, \mathrm{Zn}-\mathrm{SOD}, \mathrm{Cu}$ - and $\mathrm{Zn}$-containing superoxide dismutase; Mn-SOD, Mn-containing superoxide dismutase; Trx1, thioredoxin-1; Trx2, thioredoxin-2; HIF-1 $\alpha$, hypoxia-inducible factor 1- $\alpha$; SIc2a1, GLUT1; SIc2a3, GLUT3; SIc7a1, cationic amino acid transporter 1; SIc38a2, system A amino acid transporter gene Slc38a2; SIc38a4, system A amino acid transporter gene Slc38a4. 
Table 3. Effects of the experimental diets on fetal and placental development and the concentrations of maternal-circulating metabolites (Mean values and standard deviations)

\begin{tabular}{|c|c|c|c|c|c|c|c|c|}
\hline \multirow[b]{2}{*}{ Parameters } & \multicolumn{2}{|c|}{ C } & \multicolumn{2}{|c|}{ HF } & \multicolumn{2}{|c|}{ HFF } & \multicolumn{2}{|c|}{ NAC } \\
\hline & Mean & SD & Mean & SD & Mean & SD & Mean & SD \\
\hline Maternal body weight on day 19 (g) & 318 & 21 & 341 & 25 & 327 & 35 & 336 & 25 \\
\hline Food intake $(\mathrm{g} / \mathrm{d})$ & 18. 32 & $2 \cdot 17$ & $17 \cdot 49$ & 1.95 & $18 \cdot 27$ & $2 \cdot 64$ & $17 \cdot 33$ & $2 \cdot 0$ \\
\hline Energy intake (kJ/d) & $357^{\mathrm{a}}$ & 21 & $409^{b}$ & 12 & $380^{\mathrm{b}}$ & 20 & $405^{\mathrm{b}}$ & 18 \\
\hline Fetal weight $(\mathrm{g})^{\star}$ & 2.41 & 0.21 & $2 \cdot 38$ & $0 \cdot 10$ & $2 \cdot 53$ & 0.13 & $2 \cdot 39$ & 0.19 \\
\hline Placental weight $(\mathrm{g})^{\star}$ & $0.48^{a}$ & 0.03 & $0.50^{\mathrm{a}}$ & 0.05 & $0.56^{\mathrm{b}}$ & 0.06 & $0.51^{\mathrm{a}}$ & 0.05 \\
\hline Fetal number ${ }^{*}$ & $10 \cdot 33^{a}$ & 0.81 & $10 \cdot 00^{\mathrm{a}}$ & 0.89 & $12 \cdot 33^{b}$ & 0.82 & $10 \cdot 67^{\mathrm{a}}$ & 1.03 \\
\hline Glucose (mmol/l) & $6 \cdot 43^{\mathrm{b}}$ & 0.69 & $4 \cdot 50^{\mathrm{a}}$ & 0.80 & $6 \cdot 73^{b}$ & 1.56 & $6 \cdot 18^{a, b}$ & $1 \cdot 14$ \\
\hline TAG (mmol/l) & $4 \cdot 11^{\mathrm{a}}$ & 0.18 & $9.58^{\mathrm{c}}$ & 1.38 & $7 \cdot 85^{b, c}$ & 1.55 & $7 \cdot 32^{\mathrm{b}}$ & $1 \cdot 13$ \\
\hline $\mathrm{HDL}(\mathrm{mmol} / \mathrm{l})$ & $1.46^{\mathrm{b}}$ & 0.19 & $1.43^{\mathrm{b}}$ & 0.29 & $1.44^{\mathrm{b}}$ & 0.11 & $1 \cdot 10^{\mathrm{a}}$ & 0.16 \\
\hline
\end{tabular}

C, control group; HF, high-fat group; HFF, high-fat and high-fibre group; NAC, $N$-acetylcysteine group.

$a, b, c$ Mean values within a row with unlike superscript letters were significantly different $(P<0.05)$.

* Statistical analyses of fetal and placental weights and fetal numbers were based on the average value in each litter.

Cycler (CHRMO4-TM Thermal Cycler; Bio-Rad, Hercules, CA, USA) according to the manufacturer's instructions and the following protocol: $95^{\circ} \mathrm{C}$ for $10 \mathrm{~s}$, forty cycles at $95^{\circ} \mathrm{C}$ for $5 \mathrm{~s}$ and $60^{\circ} \mathrm{C}$ for $25 \mathrm{~s}$. Melting curve conditions were from 65 to $95^{\circ} \mathrm{C}$, reading every $0.5^{\circ} \mathrm{C}$ and holding for $5 \mathrm{~s}$ every $0.5^{\circ} \mathrm{C}$ (temperature change velocity $0.5^{\circ} \mathrm{C}$ ). The relative gene expression levels were normalised to those of the eukaryotic housekeeping gene, $\beta$-actin.

\section{Statistical analyses}

Data are presented as means and standard deviations. All data were analysed using one-way ANOVA. $P<0.05$ was considered statistically significant.

\section{Results}

\section{Reproductive performance}

As shown in Table 3, there were no significant differences in maternal body weight and daily food intake during the $19.5 \mathrm{~d}$ experimental period among the four diets. In HFF rats, fetal weight tended to increase $(P=0.052)$ and placental weight and fetal number were significantly higher $(P<0.05)$ than in the other groups.

\section{Maternal blood characteristics}

The concentrations of circulating metabolites in maternal serum are shown in Table 3. In HF rats, the maternal serum glucose level was below that in the NAC group ( $P>0.05)$ and was significantly lower than that in the $\mathrm{C}$ and HFF rats $(P<0.05)$. In addition, TAG concentration was significantly higher than that in the $\mathrm{C}$ and NAC groups $(P<0 \cdot 05)$. HDL was lowest in NAC rats $(P<0 \cdot 05)$.

\section{Placental histology}

Feeding the HF diet had an adverse effect on placental tissue integrity (Fig. 1). In the HF group, placental trophoblasts exhibited evident malformation and were partially necrotic, indicating that consumption of a HF diet had a deleterious effect on placental tissue integrity; however, dietary fibre and NAC supplementation obviously alleviated the phenomenon. In particular, the cellular structure and morphology in the HFF group were better than those in the NAC group.

\section{Superoxide anion and hydroxyl radical scavenging capacities in maternal serum and the placenta}

Figs. 2 and 3 show the superoxide anion and hydroxyl radical scavenging capacities in maternal serum and the placenta. Maternal consumption of the HF diet significantly decreased the maternal serum and placental superoxide anion and hydroxyl radical scavenging capacities $(P<0.05)$. This decrease was not evident in the HFF group $(P<0.05)$, and the serum and placental scavenging capacities in these rats remained similar to those of the $\mathrm{C}$ group. In the NAC group, the maternal serum and placental superoxide anion and
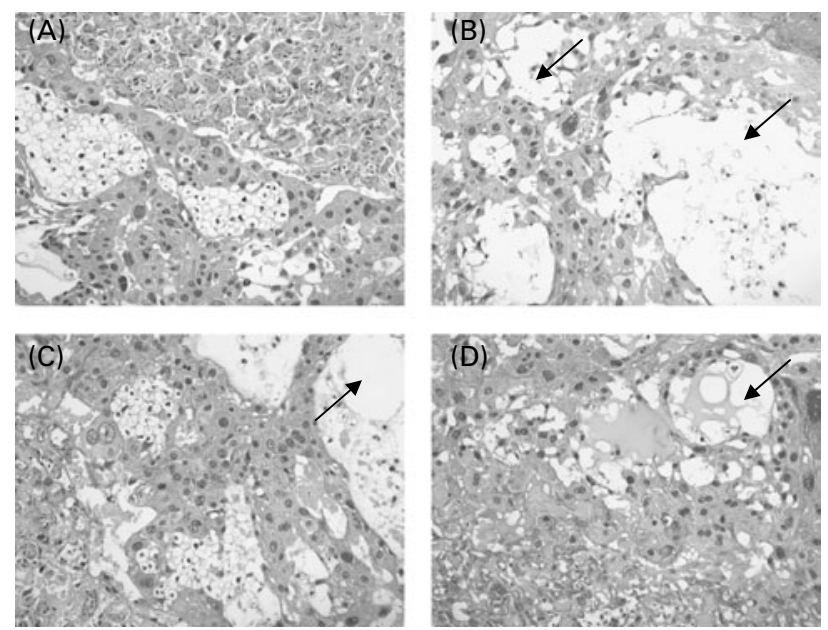

Fig. 1. Effects of the experimental diets on placental structure. (A) Control group (C), the structure was typical of a normal placenta; (B) high-fat group, the structure showed pronounced placental pathology; (C) high-fat and highfibre group (HFF), the structure showed some morphological changes compared with the $\mathrm{C}$ group, but the pathology was not as pronounced as in the HF group. Placental morphological changes are identified by black arrows (magnification $200 \times$ ). (D) NAC, $\mathrm{N}$-acetylcysteine group. 


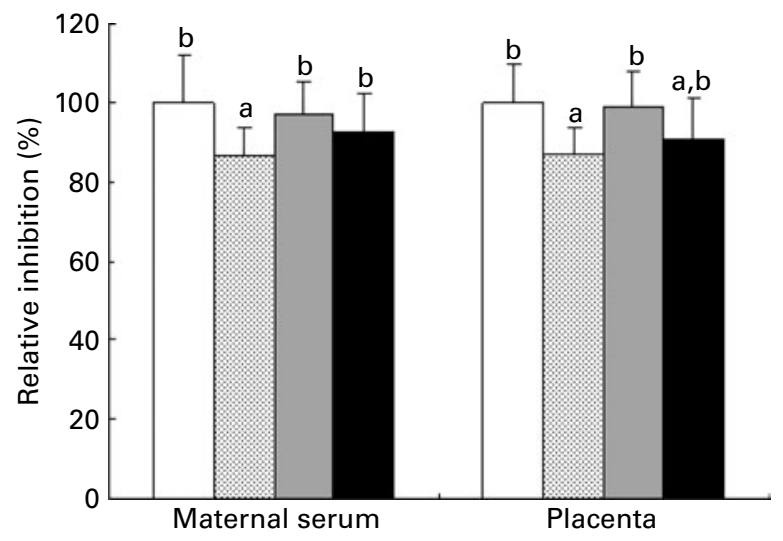

Fig. 2. Effects of the experimental diets on superoxide anion scavenging capacity in maternal serum and the placenta. The data represent the percentage superoxide anion capacity remaining compared with the control group ( $\square)$. Values are means, with standard deviations represented by vertical bars $(n 6)$. ${ }^{\mathrm{a}, \mathrm{b}}$ Mean values with unlike letters were significantly different $(P<0.05)$. .0 , High-fat group; $\square$, high-fat and high-fibre group; $\mathbf{\square}, \mathrm{N}$-acetylcysteine group.

hydroxyl radical scavenging capacities were significantly higher than those in the HF group $(P<0.05)$, and were not significantly different from those in the HFF and $C$ groups $(P>0 \cdot 05)$.

\section{Malondialdehyde and protein carbonyl content concentrations in maternal serum and the placenta}

MDA and protein carbonyl concentrations in maternal serum and the placenta were significantly increased in the HF group than in the $\mathrm{C}$ group $(P<0.05$, Table 4). Placental MDA and protein carbonyl concentrations in serum were similar between the HFF and C treatments, although MDA in serum and protein carbonyl concentrations in the placenta were still higher in the HFF treatment than in the $C$ treatment $(P<0 \cdot 05)$. However, all four variables were significantly higher in the NAC treatment than in the $\mathrm{C}$ treatment $(P<0.05)$.

\section{Antioxidant enzymatic activities in fetal liver}

The activities of antioxidant enzymes in fetal liver are shown in Fig. 4. Maternal consumption of the HF diet significantly decreased T-SOD and $\mathrm{Cu}, \mathrm{Zn}-\mathrm{SOD}$ activities in fetal liver compared with the $\mathrm{C}$ group $(P<0.05)$. In the HFF group, T-SOD, $\mathrm{Cu}, \mathrm{Zn}-\mathrm{SOD}$ and $\mathrm{Mn}-\mathrm{SOD}$ activities were significantly higher than those in the HF group $(P<0.05)$ but were not different from those in the $\mathrm{C}$ group $(P>0.05)$. There were no significant differences between the NAC and HF groups $(P>0 \cdot 05)$.

\section{mRNA expression levels of fetal antioxidant-related genes}

The mRNA expression levels of antioxidant genes and hypoxia-inducible factor $1-\alpha$ (HIF-1 $\alpha)$ in fetal liver are shown in Fig. 5. In HF rats, there was a significant suppression of the mRNA expression levels of Trx1, Cu,Zn-SOD and glutathione peroxidase 1 in fetal liver relative to the $\mathrm{C}$ group
$(P<0.05)$. In the HFF group, there was a significant upregulation in the mRNA expression levels of HIF-1 $\alpha$, Trx2 and $\mathrm{Mn}$-SOD in fetal liver relative to the $\mathrm{C}$ group $(P<0.05)$; and the mRNA expression levels of Trx1 and glutathione peroxidase 1 were higher than those in the HF group $(P<0 \cdot 05)$.

In maternal rats fed the HF diet, the mRNA expression levels of Trx1, Mn-SOD and HIF- $1 \alpha$ in fetal heart were significantly lower than those in the other groups $(P<0.05$; Fig. 6). In HFF rats, the mRNA expression level of Mn-SOD in fetal heart was significantly higher than that in the other groups $(P<0.05)$, but the mRNA expression levels of HIF-1 $\alpha$, Trx1 and $\mathrm{Cu}, \mathrm{Zn}-\mathrm{SOD}$ were not significantly different from those in the $\mathrm{C}$ group. In the NAC group, there was no change in the expression levels of antioxidant-related genes in fetal liver relative to the HF group, but increases in the mRNA expression levels of Trx1, Mn-SOD and HIF- $1 \alpha$ in fetal heart were observed $(P<0.05)$.

\section{mRNA expression of placental nutrient transporter genes}

The mRNA expression levels of placental nutrient transporterrelated genes are shown in Fig. 7. In maternal rats fed the HF diet, there was a significant up-regulation in the mRNA expression level of the cationic amino acid transporter Slc7a1 $(P<0.05)$, but there were no significant differences in the mRNA expression levels of the system A amino acid transporter genes Slc38a2 and Slc38a4 (encoding SNAT2 and SNAT4), and the GLUT genes Slc2a1 and Slc2a3 (encoding the GLUT1 and GLUT3), compared with the C group $(P>0.05)$. The HFF group showed a significant up-regulation in the mRNA expression levels of Slc2a1, Slc2a3 and HIF-1 $\alpha$ compared with the HF and $\mathrm{C}$ groups $(P<0.05)$. However, no significant differences in the mRNA levels of Slc38a2, Slc38a4 and Slc2a3 were observed between the NAC and C groups. There were no changes in the mRNA expression level of Slc38a4 among all the experimental groups.

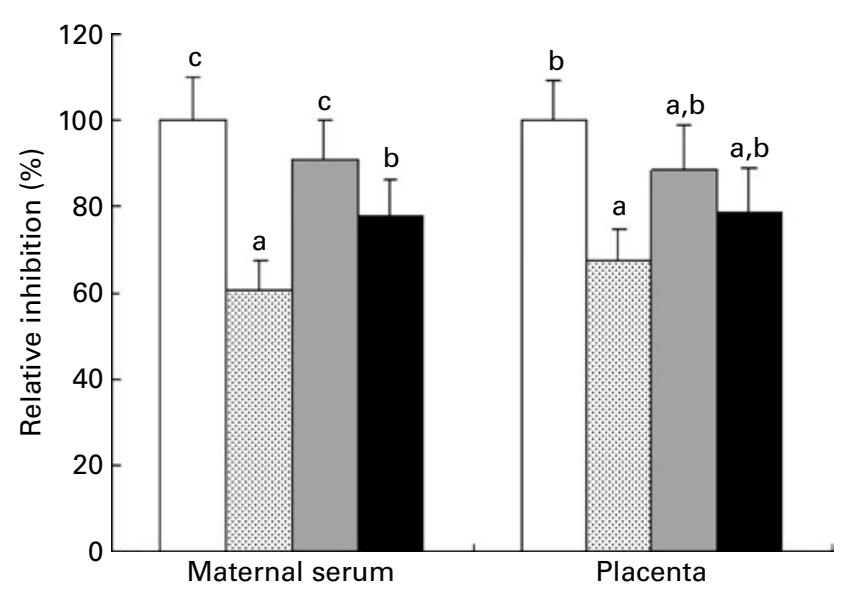

Fig. 3. Effects of the experimental diets on the hydroxyl radical scavenging capacity in maternal serum and the placenta. The data represent the percentage hydroxyl radical scavenging capacity remaining compared with the control group ( $\square$ ). Values are means, with standard deviations represented by vertical bars $(n 6)$. ${ }^{a, b, c}$ Mean values with unlike letters were significantly different $(P<0.05)$. $⿴$, High-fat group; $\square$, high-fat and high-fibre group; $\square$ $\mathrm{N}$-acetylcysteine group. 
Table 4. Effects of the experimental diets on the content of malondialdehyde and protein carbonyl (nmol/mg protein) in maternal serum and the placenta

(Mean values and standard deviations, $n 6$ )

\begin{tabular}{|c|c|c|c|c|c|c|c|c|}
\hline \multirow[b]{2}{*}{ Parameters } & \multicolumn{2}{|c|}{ C } & \multicolumn{2}{|c|}{$\mathrm{HF}$} & \multicolumn{2}{|c|}{ HFF } & \multicolumn{2}{|c|}{ NAC } \\
\hline & Mean & SD & Mean & SD & Mean & SD & Mean & SD \\
\hline Maternal serum malondialdehyde & $14.79^{a}$ & 1.79 & $27.94^{c}$ & 3.07 & $17.47^{b}$ & $2 \cdot 23$ & $22 \cdot 63^{b}$ & $2 \cdot 91$ \\
\hline Placental malondialdehyde & $0.86^{a}$ & 0.12 & $2.96^{\mathrm{b}}$ & 0.35 & $1.05^{\mathrm{a}}$ & 0.26 & $2 \cdot 39^{\mathrm{b}}$ & 0.50 \\
\hline Maternal serum protein carbonyl & $15 \cdot 57^{\mathrm{a}}$ & 1.66 & $25 \cdot 37^{\mathrm{c}}$ & 2.92 & $18 \cdot 75^{\mathrm{a}, \mathrm{b}}$ & $2 \cdot 36$ & $19 \cdot 83^{\mathrm{b}}$ & 1.11 \\
\hline Placental protein carbonyl & $20 \cdot 37^{\mathrm{a}}$ & $4 \cdot 12$ & $37.19^{\mathrm{C}}$ & 0.91 & $29 \cdot 34^{\mathrm{b}}$ & 0.94 & $32 \cdot 88^{\mathrm{b}}$ & 2.72 \\
\hline
\end{tabular}

C, control group; HF, high-fat group; HFF, high-fat and high-fibre group; NAC, N-acetylcysteine group.

${ }^{a, b, c}$ Mean values within a row with unlike superscript letters were significantly different $(P<0.05)$.

\section{Discussion}

ROS, including the superoxide anion radical and the hydroxyl radical, are formed as a result of the successive one-electron reduction of molecular oxygen. The generation of ROS is an intrinsic characteristic of any living cell and is therefore a consequence of embryo development and metabolism. ROS are beneficial as they serve as key signalling molecules in essential physiological pathways, but they also have a role in pathological processes, including those involving the female reproductive tract ${ }^{(22)}$. The present study showed that maternal consumption of a HF diet during pregnancy decreased fetus number and the scavenging capacities of maternal and placental radicals, and increased the end products of lipid and protein peroxidation. The present results are in accordance with those of other studies, which have shown that failure of implantation and fetal resorption during gestation were increased in female rats fed a $\mathrm{HF}$ diet ${ }^{(23)}$, suggesting that a HF diet is detrimental to embryo development due to high oxidative stress. Taken together, these data indicate that HF diets are associated with maternal and fetal oxidative stress and are detrimental to fetal development. Recent reports have shown that the placenta is both the target of maternal oxidative stress and a modulator of fetal oxidative stress ${ }^{(24)}$, and placental oxidative stress contributes to early fetal loss ${ }^{(5,11)}$. Based on these observations, the present results suggest that the maternal redox state transfers to the placenta and the fetus, and affects fetal development and survival.

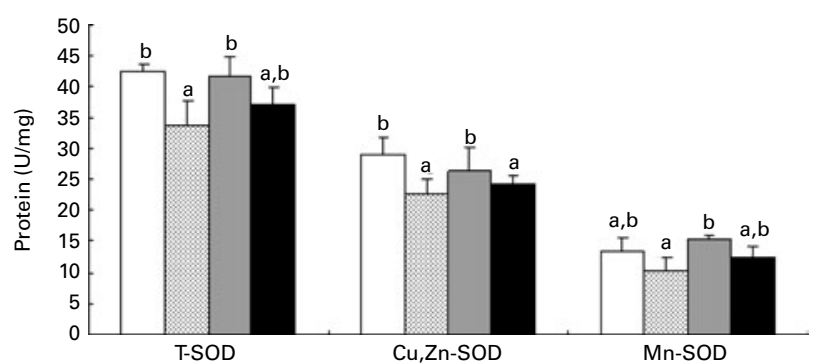

Fig. 4. Effects of the experimental diets on enzyme activities in fetal liver. Values are means, with standard deviations represented by vertical bars ( $n$ 6). ${ }^{\text {a,b }}$ Mean values with unlike letters were significantly different $(P<0.05)$. T-SOD, total superoxide dismutase; $\mathrm{Cu}, \mathrm{Zn}-\mathrm{SOD}$, copper- and zinc-containing superoxide dismutase; Mn-SOD, manganese-containing superoxide dismutase. $\square$, Control group; $⿴$, high-fat group; $\square$, high-fat and high-fibre group; $\boldsymbol{\square}, \mathrm{N}$-acetylcysteine group.
We found that maternal fibre consumption significantly increased fetal number and placental weight, and decreased placental MDA and protein carbonyl levels. These results are consistent with those of previous studies ${ }^{(25,26)}$, and suggest that supplementation of a HF diet with fibre abrogates highfat-induced oxidative stress. Fibre interferes with fat digestion and absorption in the intestinal tract, and facilitates the excretion of dietary fat into the faeces ${ }^{(27,28)}$. In addition, the fermentation of dietary fibre in the gut produces SCFA, including butyrate and acetate, which prevent $\mathrm{H}_{2} \mathrm{O}_{2}$-induced DNA and cell damage ${ }^{(29)}$. Butyrate also increases the activity of glutathione $S$-transferase ${ }^{(30)}$, a family of enzymes that utilise glutathione in reactions contributing to the transformation and detoxification of the products of oxidative stress. Based on these data, and the knowledge that NAC elevates intracellular glutathione, we investigated the role of NAC during the dietary fibre-induced abrogation of the effects of a HF diet on maternal and fetal redox status. The present results indicated that NAC increased fetal number and placental weight, and decreased the levels of placental biomarkers of oxidative stress, but that these beneficial effects were significantly lower than those of fibre. Furthermore, as there is no scientific evidence showing that changes in NAC activity are associated with the metabolism of dietary fat, we propose that dietary

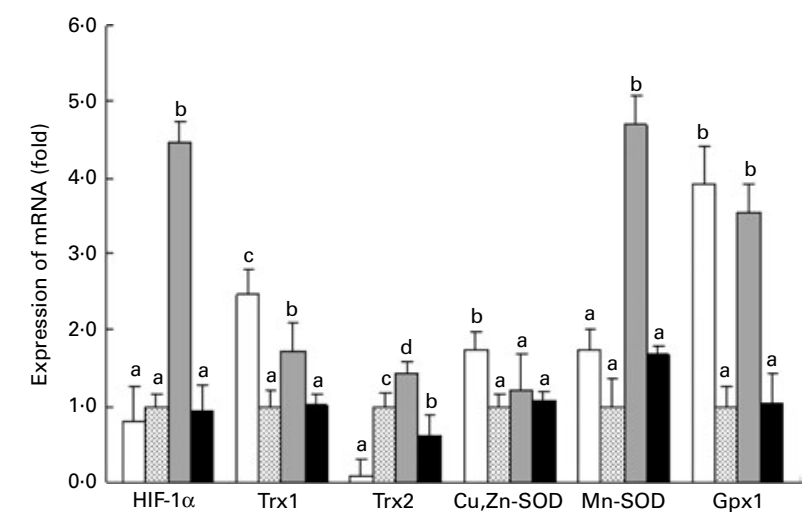

Fig. 5. Effects of the experimental diets on the mRNA levels of antioxidantrelated genes in fetal liver. Values are means, with standard deviations represented by vertical bars $(n 6)$. ${ }^{\mathrm{a}, \mathrm{b}, \mathrm{c}, \mathrm{d}}$ Mean values with unlike letters were significantly different $(P<0.05)$. HIF-1 $\alpha$, hypoxia-inducible factor $1-\alpha$; Trx1, thioredoxin-1; Trx2, thioredoxin-2; Cu,Zn-SOD, copper- and zinc-containing superoxide dismutase; Mn-SOD, manganese-containing superoxide dismutase; GPx1, glutathione peroxidase 1. $\square$, Control group; $\square$, high-fat group; $\square$, high-fat and high-fibre group; $\mathbf{\square}, \mathrm{N}$-acetylcysteine group. 


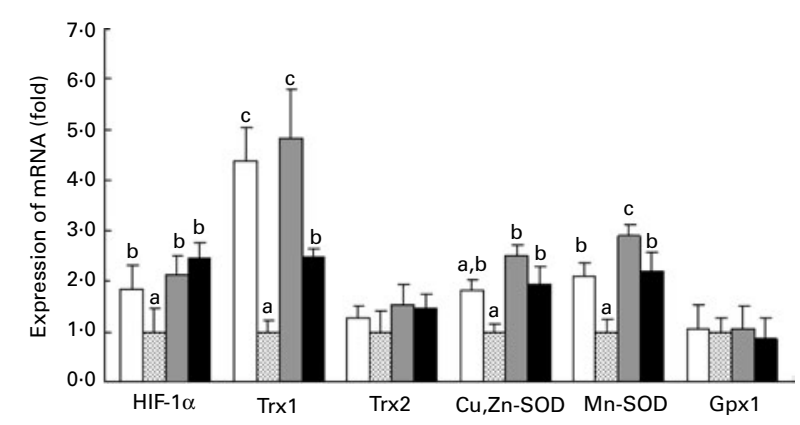

Fig. 6. Effects of the experimental diets on the mRNA levels of antioxidantrelated genes in fetal heart. Values are means, with standard deviations represented by vertical bars $(n 6) .{ }^{a, b, c}$ Mean values with unlike letters were significantly different $(P<0.05)$. HIF-1 $\alpha$, hypoxia-inducible factor $1-\alpha$; Trx1, thioredoxin-1; Trx2, thioredoxin-2; Cu,Zn-SOD, copper- and zinc-containing superoxide dismutase; Mn-SOD, manganese-containing superoxide dismutase; GPx1, glutathione peroxidase 1. $\square$, Control group; 8 , high-fat group; $\square$, high-fat and high-fibre group; $\mathbf{\square}, \mathrm{N}$-acetylcysteine group.

fibre does not abrogate HF diet-induced oxidative stress by a pathway that directly involves NAC. We suggest that the increases in faecal lipid excretion and SCFA syntheses are of primary importance during the dietary fibre-induced reduction in maternal and fetal oxidative stress and the subsequent increase in the rate of fetal survival.

The oxidative stress programming hypothesis ${ }^{(31)}$ states that oxidative stress is a key link in the fetal or developmental programming of disease. In accordance with this, previous studies have shown that maternal and fetal oxidative status was related $^{(14,32)}$; that maternal redox status affected transcription factors and altered gene expression in the fetus ${ }^{(33)}$; that eighteen gene transcripts including Cu,Zn-SOD, Mn-SOD and glutathione peroxidase 1 were down-regulated at least twofold in rats fed a HF diet; and that antioxidant supplementation completely and partially normalised four and twelve of these gene transcripts, respectively ${ }^{(34)}$. Other studies have suggested that a HF diet could cause oxidative damage to

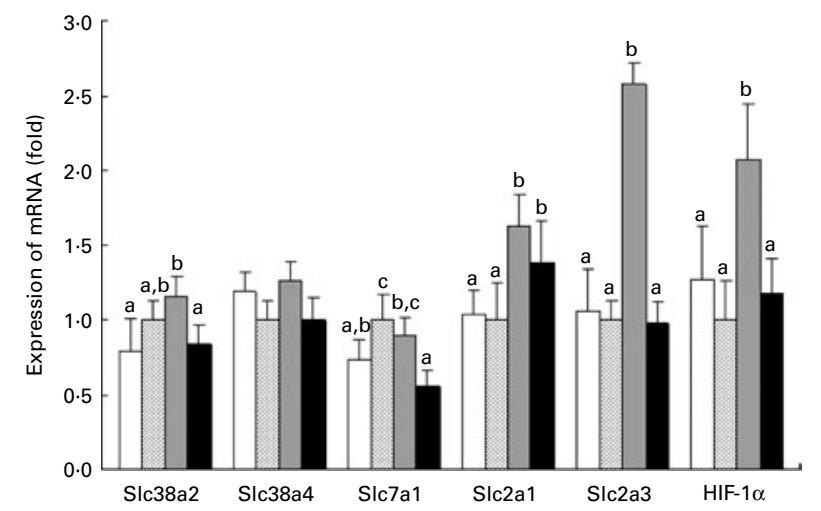

Fig. 7. Effects of the experimental diets on the mRNA levels of nutrient transporters and hypoxia-inducible factor $1-\alpha(\mathrm{HIF}-1 \alpha)$ in the placenta. Values are means, with standard deviations represented by vertical bars $(n 6){ }^{a, b, c}$ Mean values with unlike letters were significantly different $(P<0.05)$. Slc38a2, system A amino acid transporter gene Slc38a2; Slc38a4, system A amino acid transporter gene Slc38a4; Slc7a1, cationic amino acid transporter 1; Slc2a1, GLUT1; SIc2a3, GLUT3. $\square$, Control group; : $:$, high-fat group; $\square$, high-fat and high-fibre group; $\mathbf{\square}, \mathrm{N}$-acetylcysteine group.
DNA molecules ${ }^{(35)}$ and lead to lower mRNA expression levels of antioxidant defence genes; and that dietary fibre effectively reduced DNA oxidative damage induced by $\operatorname{ROS}^{(36)}$ by the up-regulation of antioxidant defence genes. In accordance with these data, we found that a high-fat maternal diet down-regulated the mRNA expression levels of several antioxidant-related genes in the fetal heart and liver, and that these transcripts were up-regulated by maternal supplementation with fibre, and to a lesser extent with NAC. In addition, we observed a marked increase in the activities of SOD in fetal liver with the inclusion of dietary fibre in a high-fat maternal diet. These results suggest that maternal dietary fibre intake during pregnancy reduces oxidative stress in the mother, improves the fetal redox state and, according to the oxidative stress programming hypothesis, may program the susceptibility of the fetus to oxidative stress after birth.

All the metabolic demands of fetal growth are provided by transplacental exchange. The placenta can respond to fetal demand signals through regulation in the expression of specific placental transport systems ${ }^{(37)}$. Slc2a1 and Slc2a3 represent the major GLUT in the human placenta ${ }^{(38)}$; the system A amino acid transporter, Slc38a2 and Slc384, mediates the transport of neutral amino acids; and cationic amino acid transporter $1 /$ Slc7a1 controls the transport of cationic amino acid ${ }^{(39)}$. The present results showed that dietary fibre supplementation of a maternal HF diet significantly up-regulated the mRNA expressions of placental Slc2a1, Slc2a3 and Slc38a2, but the mRNA expression of Slc7a1 was lower than that in the HF group. We propose that the higher fetal number in the HFF group was attributable to up-regulation in the nutrient transfer capacity of the placenta. Marked up-regulation in placental nutrient transport was observed in C57/BL6 mice after maternal exposure to a HF diet before and during pregnancy ${ }^{(40)}$; but previous reports describing the effects of maternal dietary fibre on the expression of nutrient transfer genes in the placenta during pregnancy are limited. Evidence suggests that maternal low protein intakes down-regulated the activity of transporters for system $\mathrm{A}$ and cationic amino acids $^{(41)}$, and that decreased expressions of Slc2a1 and Slc2a3 in the fetal placenta were related to fetal intra-uterine growth restriction ${ }^{(42)}$. Prolonged maternal malnutrition during late gestation decreased placental GLUT3 expression and maternal plasma glucose content ${ }^{(43)}$, and intra-uterine growth restriction in human pregnancies was associated with a down-regulation of several important placental amino acid transporters $^{(44)}$. Taken together, these data and the present results suggest that increasing maternal fibre intake during pregnancy improves fetal development by the up-regulation of specific nutrient transporters.

Recently, it has been reported that the placental mRNA expression level of HIF-1 $\alpha$ was significantly up-regulated after maternal supplementation with dietary fibre. HIF-1 $\alpha$ is a transcription factor directly or indirectly regulated by the cell redox state ${ }^{(45,46)}$ and is essential for fetal development ${ }^{(47)}$. We found that the expression of HIF-1 $\alpha$ in the fetal placenta was associated with the up-regulated expressions of Slc2a1 and Slc2a3. This is in accordance with previous studies that have shown HIF-1 $\alpha$ to be involved in the regulation of 
glycolysis ${ }^{(48)}$ and the expression of Slc2a $1^{(49)}$. We propose that HIF- $1 \alpha$ activates downstream genes, including placental glucose transport 1 and vascular endothelial growth factor, which are advantageous for fetal growth. Interestingly, previous research revealed that a close relationship was observed between ROS and HIF- $1 \alpha$ transcription $^{(50)}$; that HIF-1 overexpression conferred increased resistance to heat and oxidative stress $^{(51)}$; and that HIF-mediated hypoxia responses reduced the expressions and functions of system A amino acid transporters in cultured term human trophoblasts ${ }^{(52)}$. These data indicate that ROS is involved in HIF-1 $\alpha$ transcription and support the concept that the redox state in the placenta is closely related to its nutrient transfer capacity, thus affecting fetal development. Future studies are required to validate the concept and explore the mechanisms.

In summary, the present results indicate that maternal dietary fibre consumption during pregnancy has beneficial effects on fetal intrauterine development by alleviating maternal, placental and fetal oxidative stress and by enhancing placental nutrient transfer capacity.

\section{Acknowledgements}

The present study was supported by the Educational Commission of Sichuan Province of China (09ZB056) and the National Natural Science Foundation of China (31072044). Y. L. and D. W. designed the study; Y. L., X.-f. H. and Z.-f. F. performed the study; Y. L. and L.-q. C. analysed the data and wrote the manuscript; J. N. and T.-h. Y. assisted in writing the manuscript. The authors declare no conflict of interest.

\section{References}

1. Schafer FQ \& Buettner GR (2001) Redox environment of the cell as viewed through the redox state of the glutathione disulfide/glutathione couple. Free Radic Biol Med 30, 1191-1212.

2. Salas-Vidal E, Lomeli H, Castro-Obregon S, et al. (1998) Reactive oxygen species participate in the control of mouse embryonic cell death. Exp Cell Res 238, 136-147.

3. Myatt L \& Cui X (2004) Oxidative stress in the placenta. Histochem Cell Biol 122, 369-382.

4. Arikan S, Konukoglu D, Arikan C, et al. (2001) Lipid peroxidation and antioxidant status in maternal and cord blood. Gynecol Obstet Invest 51, 145-149.

5. Jauniaux E, Greenwold N, Hempstock J, et al. (2003) Comparison of ultrasonographic and Doppler mapping of the intervillous circulation in normal and abnormal early pregnancies. Fertil Steril 79, 100-106.

6. Sibley C, Glazier J \& D'Souza S (1997) Placental transporter activity and expression in relation to fetal growth. Exp Physiol 82, 389-402.

7. Barker DJ (1995) Fetal origins of coronary heart disease. $\mathrm{Br}$ Med J 311, 171-174.

8. Martyn CN, Barker DJP \& Osmond C (1996) Mothers pelvic size, fetal growth and death from stroke in men. Lancet 348, 1264-1268.

9. Robinson JS, Chidzanja S, Kind K, et al. (1995) Placental control of fetal growth. Reprod Fertil Dev 7, 333-344.

10. Anderson EJ, Lustig ME, Boyle KE, et al. (2009) Mitochondrial $\mathrm{H}_{2} \mathrm{O}_{2}$ emission and cellular redox state link excess fat intake to insulin resistance in both rodents and humans. $J$ Clin Invest 119, 573-581.

11. Hempstock J, Jauniaux E, Greenwold N, et al. (2003) The contribution of placental oxidative stress to early pregnancy failure. Hum Pathol 34, 1265-1275.

12. Taylor PD \& Poston L (2007) Developmental programming of obesity in mammals. Exp Physiol 92, 287-298.

13. Molinari R, Manzi L, Ricci S, et al. (2009) Diets rich in whole wheat improve redox status and enhance immune responses in rats. Food Agr Immunol 20, 95-104.

14. Estruch R, Martínez-González MA, Corella D, et al. (2009) Effects of dietary fibre intake on risk factors for cardiovascular disease in subjects at high risk. $J$ Epidemiol Community Health 63, 582-588.

15. Moore T \& Haig D (1991) Genomic imprinting in mammalian development: a parental tug-of-war. Trends Genet 7, 45-49.

16. Elizabeth K \& Rao MNA (1990) Oxygen radical scavenging activity of curcumin. Int J Pharmaceut 58, 237-240.

17. Fontana M, Mosca L \& Rosei MA (2001) Interaction of enkephalines with oxyradicals. Biochem Pharmacol 61, $1253-1257$.

18. Buege JA \& Aust SD (1978) Microsomal lipid peroxidation. Methods Enzymol 52, 302-310.

19. Spitz DR \& Oberley LW (1989) An assay for superoxide dismutase activity in mammalian tissue homogenates. Anal Biochem 179, 8-18.

20. Sun Y, Oberley LW \& Li Y (1988) A simple method for clinical assay of superoxide dismutase. Clin Chem 34, 497-500.

21. Nagai T, Inoue I, Inoue H, et al. (2003) Preparation and antioxidant properties of water extract of propolis. Food Chem 80, 29-33.

22. Agarwal A, Prabakaran SA \& Said TM (2005) Prevention of oxidative stress injury to sperm. J Androl 26, 654-660.

23. Niculescu MD \& Lupu DS (2009) High fat diet-induced maternal obesity alters fetal hippocampal development. Int J Dev Neurosci 27, 627-633.

24. Liguori A, D'Armiento FP, Palagiano A, et al. (2007) Effect of gestational hypercholesterolaemia on omental vasoreactivity, placental enzyme activity and transplacental passage of normal and oxidised fatty acids. BJOG 114, 1547-1556.

25. Milagro FI, Campión J \& Martínez JA (2006) Weight gain induced by high-fat feeding involves increased liver oxidative stress. Obesity 14, 1118-1123.

26. Souza CG, Moreira JD, Siqueira IR, et al. (2007) Highly palatable diet consumption increases protein oxidation in rat frontal cortex and anxiety-like behavior. Life Sci $\mathbf{8 1}$, 198-203.

27. Dégen L, Halas V, Tossenberger J, et al. (2009) The impact of dietary fibre and fat levels on total tract digestibility of energy and nutrients in growing pigs and its consequence for diet formulation. Acta Agr Scand 59, 150-160.

28. Deuchi K, Kanauchi O, Imasato Y, et al. (1994) Decreasing effect of chitosan on the apparent fat digestibility by rats fed on a high-fat diet. Biosci Biotechnol Biochem 58, $1613-1616$.

29. Abrahamse SL, Pool-Zobel BL \& Rechkemmer G (1999) Potential of short chain fatty acids to modulate the induction of DNA damage and changes in the intracellular calcium concentration by oxidative stress in isolated rat distal colon cells. Carcinogenesis 20, 629-634.

30. Pool-Zobel BL, Selvaraju V, Sauer J, et al. (2005) Butyrate may enhance toxicological defense in primary, adenoma and tumor human colon cells by favorably modulating expression of glutathione $S$-transferases genes, an approach in nutrigenomics. Carcinogenesis 26, 1064-1076. 
31. Luo ZC, Fraser WD, Julien P, et al. (2006) Tracing the origins of "fetal origins" of adult diseases: programming by oxidative stress? Med Hypotheses 66, 38-44.

32. Bruin JE, Petre MA, Lehman MA, et al. (2008) Maternal nicotine exposure increases oxidative stress in the offspring. Free Radic Biol Med 44, 1919-1925.

33. Dennery PA (2004) Role of redox in fetal development and neonatal diseases. Antioxid Redox Signal 6, 147-153.

34. Sreekumar R, Unnikrishnan J, Fu A, et al. (2002) Impact of high-fat diet and antioxidant supplement on mitochondrial functions and gene transcripts in rat muscle. Am J Physiol Endocrinol Metab 282, E1055-E1061.

35. Slupphaug G, Kavli B \& Krokan HE (2003) The interacting pathways for prevention and repair of oxidative DNA damage. Mutat Res 531, 231-251.

36. Wang J, Sun BG, Cao YP, et al. (2008) Inhibitory effect of wheat bran feruloyl oligosaccharides on oxidative DNA damage in human lymphocytes. Food Chem 109, 129-136.

37. Constância M, Angiolini E, Sandovici I, et al. (2005) Adaptation of nutrient supply to fetal demand in the mouse involves interaction between the Igf2 gene and placental transporter systems. Proc Natl Acad Sci U S A $\mathbf{1 0 2}$, 19219-19224.

38. Shin BC, Fujikura K, Suzuki T, et al. (1997) Glucose transporter GLUT3 in the rat placental barrier: a possible machinery for the transplacental transfer of glucose. Endocrinology $\mathbf{1 3 8}$, 3997-4004.

39. Ayuk PT, Sibley CP, Donnai P, et al. (2000) Development and polarization of cationic amino acid transporters and regulators in the human placenta. Am J Physiol Cell Physiol 278, C1162-C1171.

40. Jones HN, Woollett LA, Barbour N, et al. (2009) High-fat diet before and during pregnancy causes marked up-regulation of placental nutrient transport and fetal overgrowth in C57/BL6 mice. FASEB J 23, 271-278.

41. Malandro MS, Beveridge MJ, Kilberg MS, et al. (1996) Effect of low-protein diet-induced intrauterine growth retardation on rat placental amino acid transport. Am J Physiol 271, C295-C303.
42. Hahn T, Barth S, Graf R, et al. (1999) Placental glucose transporter expression is regulated by glucocorticoids. J Clin Endocrinol Metab 84, 1445-1452.

43. Lesage J, Hahn D, Léonhardt M, et al. (2002) Maternal undernutrition during late gestation-induced intrauterine growth restriction in the rat is associated with impaired placental GLUT3 expression, but does not correlate with endogenous corticosterone levels. J Endocrinol 174, 37-43.

44. Dicke JM \& Henderson GI (1988) Placental amino acid uptake in normal and complicated pregnancies. Am J Med Sci 295, 223-227.

45. Taylor CT (2008) Mitochondria and cellular oxygen sensing in the HIF pathway. Biochem J 409, 19-26.

46. Chandel NS \& Schumacker PT (2000) Cellular oxygen sensing by mitochondria: old questions, new insight. J Appl Physiol 88, 1880-1889.

47. Maltepe E, Schmidt JV, Baunoch D, et al. (1997) Abnormal angiogenesis and responses to glucose and oxygen deprivation in mice lacking the protein ARNT. Nature 386, 403-407.

48. Lum JJ, Bui T, Gruber M, et al. (2007) The transcription factor HIF-1alpha plays a critical role in the growth factordependent regulation of both aerobic and anaerobic glycolysis. Genes Dev 21, 1037-1049.

49. Wenger $\mathrm{RH}$ (2002) Cellular adaptation to hypoxia: $\mathrm{O}_{2^{-}}$ sensing protein hydroxylases, hypoxia-inducible transcription factors, and $\mathrm{O}_{2}$-regulated gene expression. FASEB $J$ 16, 1151-1162.

50. Pialoux V, Hanly PJ, Foster GE, et al. (2009) Effects of exposure to intermittent hypoxia on oxidative stress and acute hypoxic ventilatory response in humans. Am J Respir Crit Care Med 180, 1002-1009.

51. Zhang Y, Shao Z, Zhai Z, et al. (2009) The HIF-1 hypoxiainducible factor modulates lifespan in C. elegans. PLoS One 4, e6348.

52. Nelson DM, Smith SD, Furesz TC, et al. (2003) Hypoxia reduces expression and function of system $\mathrm{A}$ amino acid transporters in cultured term human trophoblasts. Am J Physiol Cell Physiol 284, C310-C315. 